\title{
Papers Presented at the Annual Closed Meeting of the International Hip Society
}

\section{Editorial Comment}

\author{
Miguel E. Cabanela MD
}

Published online: 2 May 2009

(C) The Association of Bone and Joint Surgeons (B) 2009

This is the second symposium of papers presented at the August, 2008 Closed Meeting of The International Hip Society in Hong Kong. The International Hip Society is slowly evolving from a travel club to a truly international group of surgeons interested in and dedicated to hip diseases and treatment. The Society counts among its ranks members on all the world continents and thus truly is a world society. Membership occurs by invitation, and the majority of members is involved in academic activities and has published more or less extensively on hip subjects. A strong and vibrant group of Society members is interested in conservative nonreplacement (commonly termed "joint preserving") treatment alternatives for hip diseases of the young but, of course, the majority of the members are interested in joint arthroplasty. Thus, while the bulk of the papers presented are generally on joint arthroplasty, the Society encourages membership of surgeons and basic scientists interested in any aspect of hip disease.

The current symposium includes a cross-section of papers ranging from basic science topics to joint arthroplasty revision. There is an important group of papers dedicated to the results in the short and long-term of conservative nonreplacement surgeries, primarily osteotomies about the hip. The increased interest in the pelvic osteotomy for dysplasia and the understanding that dysplasia and other mechanical problems are of paramount importance in

M. E. Cabanela $(\bowtie)$

Department of Orthopedic Surgery, Mayo Clinic, 200 First Street

SW, Rochester, MN 55905, USA

e-mail: cabanela.miguel@mayo.edu the generation of later osteoarthritis is addressed in other papers about issues of blood flow in osteoarthritis, and the etiology of conditions such as protrusio acetabulae.

Basic science work comprised a substantial number of the studies presented. Prosthetic materials continue to be of a great deal of interest to orthopaedic surgeons involved in arthroplasty, and one paper deals with a new surface treatment of an old material to enhance biocompatibility. Other papers report wear related to position of components, particularly with operations in which wear remains an important issue, such as resurfacing. Stability of prosthesis is of importance both in primary and revision arthroplasty and this is also addressed in one of the papers on revision with the (now) old technique of impaction grafting.

A series of clinical papers on new bearing materials is presented, including ceramic-on-ceramic, with a paper on the fading issue of minimally invasive surgery. Another paper addresses the question of whether these materials are more effective in younger patients. Two papers study issues related to the currently popular computer navigation, both in primary hip arthroplasty and in resurfacing. There are, of course, papers on long-term results of classical prosthetic designs, and several on revision surgery, including the now well-established technique of impaction grafting, as well as new materials such as trabecular metal for acetabular reconstruction. Finally, the very important issue of infection after joint arthroplasty is addressed in an interesting paper extolling the virtues of oral antibiotics for highly resistant infections.

All in all, this symposium represents a group of truly international papers that encompass the entire field of hip surgery today. I am grateful to all the authors, but especially to Dr. Richard Brand and the editorial staff of CORR for making these papers better, and hope the readers will enjoy this work. 